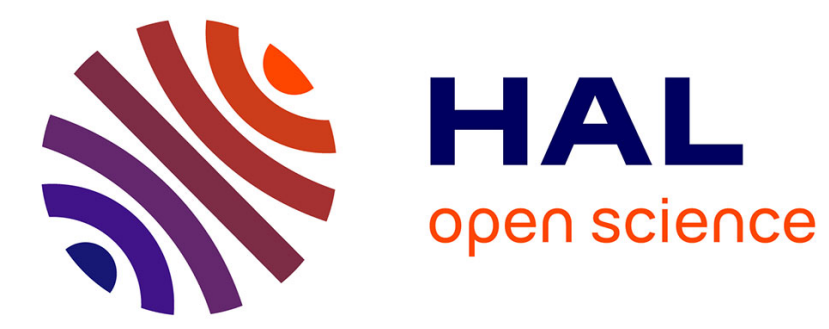

\title{
Approach to improving the quality of data used to analyse dams - Illustrations by two methods
}

\author{
C. Curt, R. Gervais
}

\section{To cite this version:}

C. Curt, R. Gervais. Approach to improving the quality of data used to analyse dams - Illustrations by two methods. European Journal of Environmental and Civil Engineering, 2014, 18 (1), pp.87-105. hal-01128843

\section{HAL Id: hal-01128843 \\ https://hal.science/hal-01128843}

Submitted on 10 Mar 2015

HAL is a multi-disciplinary open access archive for the deposit and dissemination of scientific research documents, whether they are published or not. The documents may come from teaching and research institutions in France or abroad, or from public or private research centers.
L'archive ouverte pluridisciplinaire HAL, est destinée au dépôt et à la diffusion de documents scientifiques de niveau recherche, publiés ou non, émanant des établissements d'enseignement et de recherche français ou étrangers, des laboratoires publics ou privés. 


\section{Approach to improving the quality of data used to analyse dams - Illustrations by two methods}

Corinne Curt ${ }^{\mathrm{a} *}$ and Richard Gervais ${ }^{\mathrm{b}}$

${ }^{a}$ Irstea, Hydraulic Structures and Hydrology Research Unit, Aix-en-Provence, France;

${ }^{b}$ Hydro-Québec-Règlementation et sûreté des barrages, Montréal, QC, Canada

(Received ; final version received)

* Corresponding author. Email: corinne.curt@ irstea.fr

EJECE. Volume $\mathrm{X}$ - no. x/year, pages 1 to $\mathrm{X}$ 


\title{
Approach to improving the quality of data used to analyse dams - Illustrations by two methods
}

\author{
Assessing the safety of a civil engineering structure requires using a large quantity of \\ data. These data are frequently "imperfect", meaning that they comprise uncertainty, \\ imprecision and incompleteness. It is important to develop systems for assessing and \\ controlling these imperfections in order to both quantify the quality of the data used to \\ evaluate the condition of structures and decide on the corrective actions to reduce these \\ imperfections. Here, we propose a generic approach to controlling the quality of the \\ data used when analysing a dam. Different methodologies can be considered to \\ implement this approach and an illustration is given for two methods developed \\ independently: one by Hydro-Québec, in Canada, and another, by Irstea, in France.
}

Keywords: uncertainty; monitoring; visual observation; assessment; control; dam

\section{Introduction}

Maintaining the safety of civil engineering structures greatly relies on the development of methods and decision aids that allow assessing their reliability and their condition. This is particularly the case of dams that can give rise to risks for persons and property located downstream. Different methods are available in the literature for assessing dam safety: physical models, records of failures and accidents (Foster, Fell and Spannagle, 2000a; Foster, Fell and Spannagle, 2000b; Kreuzer, 2000), systemic methods (Peyras, Royet and Boissier, 2006; Serre, Peyras, Curt, Boissier and Diab, 2007), and knowledge-based methods (Andersen and Torrey, 1995; Andersen, Chouinard, Hover and Cox, 2001; Chou, Chen, Wang, Chen and Chen, 2001; Curt, Peyras and Boissier, 2010; Curt, Talon and Mauris, 2011; Hydro-Québec, 2005; Peyras et al., 2011; Serre et al., 2007).

Knowledge-based methods rely on information analysed when examining a dam: data can originate from instrumentation (flow rate measurements, piezometric levels, etc.), visual EJECE. Volume $\mathrm{X}$ - no. x/year, pages 1 to $\mathrm{X}$ 
inspection (assessing a leak, detecting a sinkhole, etc.), computations from mathematical models (hydraulic gradient, slope stability safety factor), and design and construction records (earthwork slope, granulometry of materials, etc.).

This data is then combined to determine the condition or reliability of the dam. It contains varying degrees of imperfection that can be classified into three main types (Ben Armor and Martel, 2004; Bouchon-Meunier, 1999): imprecision, uncertainty and incompleteness. Imprecision is linked to an approximate expression of knowledge, a difficulty in expressing a situation clearly either because numerical data are poorly known, or because the terms of the language used to qualify a characteristic of the system are vague. Uncertainty expresses a doubt as to the validity of knowledge. In our case, we situate ourselves in the framework of epistemic uncertainty: this stems from insufficient knowledge, data and information, and not from natural variability resulting from stochastic phenomena (rainfall, temperature, etc.). Incompleteness is the absence of knowledge, data or information. It can be due to the impossibility of obtaining certain information (for example, no information on the design of the drainage system in the dam documents) or a problem of data collection. The various forms of imperfection are not independent: incompleteness leads to uncertainty; the more precise a formulation should be, the less certain it is. These imperfections have several sources, for instance, damage to a monitoring device (possibly leading to uncertainty), its lack of precision (leading to imprecision) or insufficient measurement frequency (leading to incompleteness) are a few reasons among others leading to imperfections introducing a bias in the data.

If the data is tainted by imperfections, assessing the performance or condition of the dam will also be skewed. Performance or condition is defined as the capability of an 
4 EJECE. Volume $\mathrm{X}-$ no. $\mathrm{x} / \mathrm{year}$

infrastructure to perform the functions for which it was designed, avoiding the occurrence of critical or disastrous events. Performance or condition integrate the reliability ("ability of a system to perform and maintain its functions, in given conditions, during a given period of time" (Villemeur, 1991)) along with the safety ("ability of a system to avoid the occurrence of critical or disastrous events in given conditions" (Villemeur, 1991)).

Reducing imperfections is important since making decisions to take adequate corrective actions on a structure is not an easy task. When controlling imperfections, it is vital to take into account their different origins so that improvements can be proposed on the system producing the data. For example, this could take the form of replacing a defective device, increasing the number of readings, controlling the vegetation on the downstream slope to allow adequate visual inspection and so forth.

In this article, we only address the data used during dam reviews: we propose a general approach to improve their quality. It is implemented in two phases: quantifying the quality of each information element used to assess the condition of the structures and determining the corrective actions on measurement systems (for instance, replacement of a device) and data processing systems (for instance, use of a software better adapted to the data processing) to reduce these imperfections. This approach will be illustrated by relying on two methods developed independently of each other: the Condition Index (CI) method implemented by Hydro-Québec and a method developed by Irstea.

The Condition Index originates from the cross-disciplinary programme REMR (Repair, Evaluation, Maintenance and Rehabilitation) set up by the US Army Corps of Engineers (USACE) at the beginning of the 1980s. A generic methodology was proposed to allocate funds rationally between a large number of structures on the basis of the assessment 
Author-produced version of the article published in European Journal of Environmental and Civil Engineering, 2014,18 (1), 87-105. The original publication is available at http://www.tandfonline.com/toc/tece20/18/1

DOI: 10.1080/19648189.2013.850188

of a condition index (Andersen and Torrey, 1995; Andersen et al., 2001). This technique was used and adapted by other organisations such as Hydro-Québec for embankment dams (Hydro-Québec, 2005). It is designed to determine, at a given moment, the condition of a dam and, also, of its monitoring system composed of instrumentation and visual observations, in order to propose corrective actions, if necessary. In this article, we focus only on the method from the angle of the monitoring system.

The data quality analysis method developed by Irstea is also designed to assess the quality of the different data used during dam analyses and to provide corrective actions if required (Talon, Curt and Boissier, in press).

The aim of this paper is to present the approach used to control data quality (Section 2) and then to describe the methodological approaches implemented in Hydro-Québec and Irstea methods (Section 3). Mention of other methodologies is also made for improving data quality in other fields.

\section{Approach to improve data quality}

Before introducing the general principles to improve data quality, we will first focus on the data used during dam analyses.

\section{Data used during dam analyses}

Generally, four types of information are used during dam inspections: visual observations, instrumentation measurements, computations resulting from mathematical models, as well as design and construction records (cf. Figure 1). Before use, instrumental indicators undergo statistical analysis to take into account external parameters such as headwater level, seasonal 
Author-produced version of the article published in European Journal of Environmental and Civil Engineering, 2014, 18 (1), 87-105. The original publication is available at http://www.tandfonline.com/toc/tece20/18/1 DOI: $10.1080 / 19648189.2013 .850188$

6 EJECE. Volume $\mathrm{X}-$ no. $\mathrm{x} / \mathrm{year}$

effects, pluviometry and time. Calculated data consists notably of: hydraulic gradient, seismic resistance, spillway capacity, slope stability safety factors. The mathematical models use, as inputs, instrumental indicators, intrinsic characteristics of the studied dam (geometry, material properties, etc.) and extrinsic characteristics (headwater level, hydrographs, etc.). These data are used to monitor the performance of all types of dam. The set of these four types of information is named "Assessment system".

[Figure 1 near here]

In a knowledge-based method, the various data of the Assessment System make up the inputs of the aggregation models used to assess the condition or performance of a structure (cf. Figure 2). These models were defined for the two methods discussed in this paper during knowledge collection sessions carried out with experts in the domain of dams. The aggregation models are IF-THEN rules, combinations of arithmetic operators, truth tables, etc. (Curt et al., 2010). If necessary, this assessment phase is followed by the corrective actions to be implemented on the structure (maintenance, repair, emergency actions). The aggregation models were developed in the case of embankment dams and gravity dams: the proposed methodology to assess the data quality can be used for these two kinds of dams.

If available data are biased by imperfections, the assessment of the performance or condition will also be influenced (cf. Figure 2). The adequate decision for corrective actions on the structure might therefore be difficult to take. Thus, it is vital to develop methods to improve the quality of the data by reducing the related imperfections. 
[Figure 2 near here]

\section{General principle of the approach to improving data quality}

The general principle of the approach to improving data quality is presented in Figure 3. It comprises three main stages: definition of the scope of the study, assessment of data quality and finally, control of data quality.

[Figure 3 near here]

The aim of the first phase is to define the framework of the study (routine maintenance, detailed engineering analysis, etc.) to select pertinent information and period of dam life-cycle to be taken into account.

The second phase concerns the assessment of the quality of the data considered. It is split into two steps: criteria definition and criteria aggregation. The former identifies pertinent criteria and defines a scoring scale while the latter produces a global quality score (QS) for the data considered. Validation sessions are planned during this stage. A group of experts is interviewed about the validity of the criteria and their scoring scale: if experts assess that criteria and scale are correctly formalised then the validation is successful. If not, experts can express remarks that are integrated and lead to alteration of criteria or measurement scale. The same process is applied concerning the aggregation method and its parameterization.

The aim of the third phase is to control data quality by proposing corrective actions to be applied to the information system. On one hand, the nature of the corrections must be 
Author-produced version of the article published in European Journal of Environmental and Civil Engineering, 2014, 18 (1), 87-105. The original publication is available at http://www.tandfonline.com/toc/tece20/18/1 DOI: $10.1080 / 19648189.2013 .850188$

8 EJECE. Volume $\mathrm{X}-$ no. $\mathrm{x} /$ year

defined and, on the other hand, the schedule and the ranking of these actions must be established on the basis of a global quality score (cf. Figure 3).

\section{Methodological approaches}

The methods developed by Hydro-Québec and Irstea both function according to the principle of the three phases described above. This is why we use them here as examples. Nonetheless, these two methods have different aims, as will be shown in the following paragraphs. These dissimilar objectives lead to the use of separate methodological approaches during the data assessment and data quality control phases. The detailed methodologies will be presented in paragraphs 3.2 to 3.4. These paragraphs also provide other potential methodological paths.

\section{Definition of the scope of the study}

\section{Definition of the system}

The first question that arises when developing data quality improvement methods concerns the definition of the system studied. In the case of data used to perform dam analyses, the system is composed by:

- a measurement system (MS) defined by a "set of one or more measuring instruments and often other devices, including any reagent and supply, assembled and adapted to give information used to generate measured quantity values within specified intervals for quantities of specified kinds" (AFNOR, 2011),

- a data processing system (DPS) composed of processing methods and tools that allows analysis or data conversion into usable information. 
Indeed, certain data are processed before being used (cf. Figure 1): for the most part, this concerns statistical processing for instrumentation data in order to eliminate disturbances such as variations of reservoir water level and achieve constant comparison conditions. Also, instrumentation data as well as design and construction records are used as inputs for mathematical models to calculate values such as hydraulic exit gradients (cf. Figure 1). Thus, the ultimate quality of the data stems from the assessment system composed of both MS and DPS.

The measurement system (MS) is composed of specific components as a function of the information required:

- instrumentation data used during the operation phase: the measurement system is composed of instruments such as piezometers, flow rate meters, etc.

- design and construction records: the measurement system is composed of equipment used to perform in situ tests and sensors used for data acquisition;

- visual observations: the measurement system is the agent (engineer, technician, dam keeper) who performs the visual observation;

- computations: as computation data come from design and instrumental data (cf. Figure 1), the measurement system is here related to the design and construction records as well as the instrumentation data.

The data processing system (DPS) concerns:

- the instrumentation data which are processed to eliminate disturbances and ensure constant comparison conditions; 
Author-produced version of the article published in European Journal of Environmental and Civil Engineering, 2014, 18 (1), 87-105. The original publication is available at http://www.tandfonline.com/toc/tece20/18/1 DOI: $10.1080 / 19648189.2013 .850188$

- the data calculated using mathematical models.

\section{Phases of the assessment system life-cycle}

A life-cycle can be determined for any physical system. For the assessment system, it is composed of design, construction, operation, and dismantling phases. In the present case, only the first three phases are liable to induce a loss of quality in the data produced during construction and operation phases. The analysis therefore focuses on studying the assessment system by considering the design, construction and operation phases:

- the design and construction phases have a major impact on data quality via the choice of MS (type of instruments, type of tests etc.), the selection of its installation location (position of instruments in the dam and foundations), and the choice of DPS (software). These phases concern all the DPS (instrumentation data processing software and mathematical model calculation software) and all the MS, with the exception of the MS-Visual Observations during the design phase.

- An example of insufficient monitoring scheme is quoted in (Pimenta and Silva Gomes, 2000): “despite the first complement of the monitoring scheme has been implemented some years ago, the need of a new complement $[\ldots]$ is stressed to have a more comprehensive monitoring of the dams". Moreover, "commercial instruments frequently become obsolete because of design changes aimed at improving their performance or introduction of new technology" (Dibiagio, 2000): changing the initial type of instruments can lead to a data quality improvement 
- the operation phase concerns all the MS and DPS: inadequate monitoring plan, problem related to the exploitation of the monitoring system or lack of maintenance constitute sources of imperfection. Insufficiently frequent data collection, carrying out tests on data that is incomplete or lacking in representativeness are all examples of imperfection sources during this phase. Inadequate data collection or deviation from monitoring plan constitutes one possible cause of data imperfection.

The following statements are examples quoted from dam safety review reports: "Unfortunately, during a long period, no drainage flow measurements were performed as if this point was forgotten in the monitoring plan", "Materials and vegetation that cover the downstream toe have to be quickly removed to free the drain outlets then specific device to collect and assess the drainage flow has to be installed". Another cause for data imperfection is the lack of representativeness when the measurement does not represent the phenomenon it should measure. For instance "A doubt exists about the representativeness of piezometers whose measurement chamber is very close to the drainage blanket or even intercept it."

Examples are presented of measurement system failures leading to a loss of data quality in the design and construction phases in Table 1, and for the operation phase, in Table 2.

[Table 1 and Table 2 near here]

\section{Objectives of the methods}

In the case of the Condition Index (CI) method, the aim of the approach is to define the relative priority of maintenance actions to be carried out on all dams for a given year. This 
Author-produced version of the article published in European Journal of Environmental and Civil Engineering, 2014, 18 (1), 87-105. The original publication is available at http://www.tandfonline.com/toc/tece20/18/1 DOI: $10.1080 / 19648189.2013 .850188$

12 EJECE. Volume $\mathrm{X}$ - no. x/year

entails developing decision tools regarding the priorities to be given to the remedial works of the monitoring system. These become necessary due to detected faults in the visual inspection and in the instrumentation. This method is driven by the impact on the safety of the dam. This type of approach provides a homogenous assessment of the different monitoring systems linked to the various structures and thus allows efficient ranking. In line with these objectives, for Hydro-Québec, it is logical to take account of the MS linked to the operation phase, which concerns only the Visual Observation MS and the Instrumentation Data MS.

In the case of the method developed by Irstea, the aim of the approach is to propose corrective actions for the whole measurement system: all the MS and DPS are studied at every pertinent phase of the life-cycle. A schedule for execution is assigned to each of the corrective actions proposed (emergency action, short term action, medium term action). As with the condition index method, the definition of criteria and scoring scales leads to a robust assessment of data quality and therefore makes it possible to define priorities for action where necessary. It therefore also forms a knowledge base oriented towards the dam assessment system. In addition to using the system as a decision aid, this type of tool is pertinent for transmitting this information to engineers relatively inexperienced in carrying out analyses and assessing the systems used to monitor structures. This objective of transmitting knowledge is relevant insofar as there are many sources of imperfection and they are specific to each of the measurement and processing systems. Also, these sources of imperfection have varying impacts on data quality and corrective actions must be defined by type of action and a schedule of execution. Thus analysing such systems is complex. 


\section{Discussion}

Other objectives can be considered. Thus a method focused on the maintenance of the dam monitoring system, which concerns only the operation phase and the measurement systems, will only take into account visual MS and instrumentation MS. If the aim is to focus on a type of data, e.g., instrumentation data, all the phases of the life-cycle for the instrumentation MS and DPS must be taken into account. This study highlights that the system to be studied differs as a function of the objective pursued (maintenance, analysis, etc.), and the number of sources of imperfection. This paper was written for dams and it should be possible to apply it to different civil engineering structures, since the four types of data identified are common to the different fields.

\section{Definition of criteria: methodologies and illustrations}

Criteria definition consists of identifying the pertinent performance parameters and defining a scoring scale for each of them.

\section{Methodology}

The criteria were defined for Irstea and Hydro-Québec during sessions dedicated to formalising the analysis. In the case of the method developed by Irstea, preparatory work was performed before the field sessions were held (Curt and Talon, 2013). It consisted in performing an FMEA (Failure Mode and Effects Analysis).

The FMEA is a qualitative method for analysing potential defects in a system by considering each of the components. It was performed for the MS and DPS, by taking into account the design, construction and operation phases which are crucial for data quality (ICOLD, 1988). This preliminary analysis permits listing of an initial group of criteria that are 
Author-produced version of the article published in European Journal of Environmental and Civil Engineering, 2014, 18 (1), $87-105$. The original publication is available at http://www.tandfonline.com/toc/tece20/18/1 DOI: $10.1080 / 19648189.2013 .850188$

EJECE. Volume X - no. x/year

then consolidated by a panel of experts. This type of approach minimizes the time required to describe the various criteria, considering experts are of limited availability. In this phase, it is also important to refer to the standards in the field of metrics, especially in order to use internationally recognised vocabulary: standard NF ISO/CEI GUIDE 99 (AFNOR, 2011), for example, is an essential basis for defining certain parameters.

Several sessions may be required to assemble all the useful criteria. Once all of them have been identified, scoring scales are defined for each one by the expert panel. It is the people responsible for data collection (technicians, dam keepers and experts) that afterwards perform the scoring when using the method in the field.

\section{Illustrations}

The chosen criteria are specific to the types of data in both methods: visual observations, instrumentation data, design and construction records, and computed values. As seen previously, the CI method uses mostly visual and instrumentation information. In the following paragraphs, attention will be paid only to these two types of data. The criteria defined in the two methods are compared in Table 3 (data resulting from instrumentation) and in Table 4 (data resulting from visual observation).

[Table 3 and Table 4 near here]

The number of criteria for evaluating a type of data varies from one method to another: thus, for visual observations, two criteria are used for the CI method while eight are used for the Irstea method. For the instrumentation data, four criteria are defined for the CI 
method while 12 are used for the Irstea method. These differences will be investigated in the next few paragraphs.

The criteria defined for the instrumentation measurements are classified into four categories (cf. Table 3). First, life-cycle phases are chosen to identify the criteria linked to MS (design, construction and operation phases) and the criteria linked to DPS. Secondly, the criteria linked to MS during the operation phase can be further subdivided into criteria related to the device and criteria related to the person responsible for collecting the instrumentation data.

As the CI method focuses on monitoring device maintenance, only the category MS Operation phase - Criteria related to the device itself is pertinent. Comparison between the Irstea and the Hydro-Québec methods with respect to this category shows that the criteria labels are very similar. The eight other criteria used by Irstea are not listed in Table 3.

The measurement precision is defined as the "closeness of the agreement between indications or measured quantity values obtained by replicate measurements on the same or similar objects under specified conditions" (AFNOR, 2011). The resolution is "the smallest change in a quantity being measured that causes a perceptible change in the corresponding indication" (AFNOR, 2011). The representativeness corresponds to the ability of the device to assess the phenomenon it was dedicated to. For instance, if a piezometer reading must be representative of the water level in the downstream shoulder, then, it must not intercept the drain.

The quality of visual inspection derives from data accessibility and inspector related parameters (cf. Table 4). In the case of the CI method, only the criteria linked to the 
Author-produced version of the article published in European Journal of Environmental and Civil Engineering, 2014, 18 (1), 87-105. The original publication is available at http://www.tandfonline.com/toc/tece20/18/1 DOI: $10.1080 / 19648189.2013 .850188$

accessibility of the data are considered as the inspectors are trained and not supposed to introduce imperfections in the data. In the Irstea method, it is considered necessary to check the competence of the inspector. These criteria are scored as excellent if the inspector is a fully trained technician and, particularly, if he or she is considered an expert.

Criteria linked to data accessibility present differences:

- frequency of inspection, which is a criterion defined in the CI method, is not used as such in the Irstea method. This frequency is imposed in the latter case and assumed to be followed by the inspectors;

- climatic conditions are not taken directly into account in the CI approach as opposed to the Irstea method. However, this criterion only applies for some visual observations: leak and wet area that might not be easily detected if rain occurs shortly before inspection.

These comparisons show that the criteria defined in the two methods are adapted to their own objectives and that constants exist.

The criteria listed in Table 4 are quoted in the literature as important factors for the quality of the data (Cajete and Gil, 2000; Degoutte, 2002; Royet, 2006). However, these papers do not propose methods for their quantification contrary to this article.

Once the various criteria have been identified, a scoring scale has to be assigned to each of them. In each of the illustrative methods, a single scoring scale permits assessing the criteria. Thus in the method developed by Irstea, the criteria are scored according to a scale from 0 (excellent) to 3 (very poor) with 1 (good) and 2 (poor). The 0-3 scale is defined with 
Author-produced version of the article published in European Journal of Environmental and Civil Engineering, 2014, 18 (1), $87-105$. The original publication is available at http://www.tandfonline.com/toc/tece20/18/1

DOI: $10.1080 / 19648189.2013 .850188$

references for each criterion. For instance, in the case of "Conditions of visibility accessibility (C1)":

- " 0 " means the downstream slope is covered of short grass;

- "1" corresponds to a downstream slope with high grass;

- " 2 " means the downstream slope is colonised by some trees or shrubs;

- " 3 " indicates the downstream slope is invaded by vegetation composed of trees and shrubs.

Table 5 shows an example of scoring for the criteria "Visibility conditions Accessibility" for the visual data "Leak on the downstream slope of the embankment". The expert assesses this criterion as 2 because some shrubs prevent a correct visual inspection.

[Table 5 near here]

In the method developed by Hydro-Québec, the various assessment criteria are scored from 0 to 100, as adapted from the USACE REMR scale (cf. Table 6):

[Table 6 near here]

This range permits reasoning on the basis of the percentage of surface area that can be inspected. Table 7 shows an example of scoring for the inspection of the downstream area during search for the existence of uncontrolled percolation. Here, the expert gave a score 
Author-produced version of the article published in European Journal of Environmental and Civil Engineering, 2014, 18 (1), 87-105. The original publication is available at http://www.tandfonline.com/toc/tece20/18/1 DOI: $10.1080 / 19648189.2013 .850188$

equal to 50 (marginal) because only shrubs are present in the slope and allow the inspection, even if difficult.

[Table 7 near here]

\section{Discussion}

In both methods, a group of experts plays an essential role in defining the various criteria: which one to keep, the choice of terms used to name them, the definition of a scoring scale (size and number of classes). It is therefore essential for this type of approach to gain the collaboration of a pool of available experts in the domain.

It is important to be exhaustive in identifying all the criteria in relation to the pursued objective. Depending on the MS and DPS considered, this identification phase can take a long time if it is only carried out during the sessions dedicated to collecting field information. We recommend using an FMEA type method and metrology concepts in order to perform a study prior to the data collection sessions in order to make the latter more efficient. Conversely, it is important to eliminate all redundant criteria from the list.

Analysis of the independence between the criteria is important for the following aggregation phase: certain aggregation methods can be used more easily than others according to the independence or non independence of the criteria.

A single assessment scale has been retained for all the criteria in the two methods used here for illustration. It is quite possible to define different scales as a function of the criteria assessed. 


\section{Aggregation of criteria}

The objective of the aggregation phase is to obtain a global score of the quality or condition for each data considered (cf. Figure 3). This information can consist, for example, of visual observations performed on the downstream slope and toe of the dam (leak detection, sinkhole investigation, etc.) or the data obtained by instrumentation (piezometers, inclinometers, etc.). The scores assigned to the different pertinent criteria for the data studied (cf. Table 3 and Table 4) can be aggregated according to the different approaches.

\section{Methodologies}

The aggregation methodologies implemented in the two illustrative methods are different.

When providing the guidelines for the CI method, care has been taken to scale the numerical range of individual criteria with respect to each other. This makes possible the use a simple Minimum operator. It is therefore easy to apply the method in the field, but expert knowledge has to be pooled to define the appropriate range of each criterion prior to this. Thus, all the criteria have the same weight with respect to the quality of the data: aggregation was performed by using the operator "Minimum"; the choice was made to retain the worst score for the assessment. This aggregation provides the condition index of a monitoring activity or device i for a dam j: $C I_{M D_{i, j}}$ (cf. Figure 4).

[Figure 4 near here] 
Author-produced version of the article published in European Journal of Environmental and Civil Engineering, 2014, 18 (1), 87-105. The original publication is available at http://www.tandfonline.com/toc/tece20/18/1 DOI: $10.1080 / 19648189.2013 .850188$

The Irstea experts assigned different weights to the various criteria. Given the number of criteria for each type of data and the associated weighting, a multi-criteria aggregation method was chosen. We showed that the ELECTRE TRI multi-criteria method (Maystre, Pictet and Simos, 1994; Roy, 1985) was that best-suited to our problem (Curt and Talon, 2013). ELECTRE TRI is applied to a problem of segmentation that consists in analysing the intrinsic value of the data studied through the criteria that characterise it and assigning a number of ordered categories to this data, in this case: 1 ("Excellent") to 5 ("Unacceptable") with, in between, 2 ("Good"), 3 ("Mediocre") and 4 ("Bad"). It relies on a comparative study between each indicator and the reference profiles that characterize the limits of each category and uses the concept of outranking. For further details on the methodology, see: Maystre et al. (1994), Roy (1985), Roy (1996), Roy and Bouyssou (1993). For further details on the application of ELECTRE TRI for the assessment of data quality, see: (Curt and Talon, 2013). The aggregation therefore reaches a quality score QS (cf. Figure 4). This type of method has to be parameterised. Two types of methods are used to determine the parameter values. The criteria weights are defined by experts during elicitation sessions such as performed in (Brito, Almeida and Mota, 2010; Merad, Verdel and Kouniali, 2004). The other parameters (preference and indifference thresholds) are obtained using inference from examples (Mousseau and Slowinski, 1998; Nafi and Werey, 2009) because the direct elicitation of these parameters is rather difficult. We determine the value of the parameters using examples processed by experts: they assessed the criteria and attributed a global quality score $Q S_{\text {Exp }}$. Furthermore, $Q S_{\text {ETRI }}$ was calculated with ELECTRE TRI by using different values to fit the different parameters. The parameters were therefore fixed so as to minimise the difference between $Q S_{E x p}$ and $Q S_{E T R I}$. During the validation step, new cases were assessed 
by the experts and by the ELECTRE TRI algorithm: the differences between $Q S_{E x p}$ and $Q S_{E T R I}$ were not significant.

A calculation tool was developed to assess QS.

\section{Illustration}

Table 8 provides an example of aggregation by the ELECTRE TRI method of values linked by an expert to different criteria for one datum.

[Table 8 near here]

These different criteria, $\mathrm{C} 1$ to $\mathrm{C} 8$, have two different weights linked to their importance defined by the experts: essential criterion and important criterion. The weighting coefficients are calculated as follows:

$$
\begin{aligned}
& x_{e}=2 x \\
& x_{i}=x \\
& \sum\left(x_{e}, x_{i}\right)=100
\end{aligned}
$$

with:

- $\mathrm{x}_{\mathrm{e}}$ the weighting coefficient for essential criteria;

- $\mathrm{x}_{\mathrm{i}}$ the weighting coefficient for important criteria.

For "Cracks in the joints between blocks", the criterion "climatic conditions" (C2) has no influence on the quality of the information, thus its weight is nil. 
The quality of this indicator is assessed as "poor" (QS =3).

\section{Discussion}

Two different aggregation methods were chosen: one for an arithmetic operator, the other by a multi-criteria aggregation method. Other methodologies are also available such as:

- IF-THEN rules: IF C1 $=\mathrm{a}$ and IF C2 $=\mathrm{b}$ and IF C3 $=\mathrm{c}$ and IF $=\mathrm{d}$ THEN QS $=\mathrm{e}$. This type of approach can be useful in the case where the number of criteria is lower than 7. Indeed, it is difficult for the human mind to deal with more than 7 concepts (Miller, 1994);

- neural networks, regressions, etc.

The choice for the method to be used must take into account the number of criteria to be aggregated, their relative weights, their possible interactions, etc.

For methods requiring fitting parameters or learning (multi-criteria methods, neural networks, etc.), it is necessary to have a case database to parameterise the method. Afterwards, a different database from that used for parameterisation must serve to validate the aggregation tool.

The aggregation models are validated by comparing the quality of the data declared by a group of experts and the quality calculated by the models. Therefore it is necessary in this validation stage to again retain the collaboration of a panel of experts.

\section{Controlling data quality}

The aim of this step is to determine the appropriate corrective actions to be applied to the 
system in order to improve data quality. Two elements are important: the nature of the actions and their schedule or priority.

\section{Methods}

Different types of corrective actions can be considered: maintenance, repair, additional inspections and instrumentation, emergency actions, etc. In the two methods these corrective actions derive from field information recording sessions. One difference between the two approaches stems from the fact that in the Irstea method, the actions are predefined for each of the criteria. For example, for visual observation data, the activation of criterion $\mathrm{C} 1$ ("Visibility Conditions - Accessibility") will trigger associated maintenance actions (cleaning of drain outlets, limiting the vegetation on the downstream slope, etc.). The list of possible actions is finite and relatively short. They correspond to inspection, maintenance and repair tasks performed routinely in civil engineering. On the other hand, there is no predetermined list of actions in the CI method. The experts must define the adequate corrective actions to be performed for each case.

The second essential task in determining corrective actions is to provide either an execution schedule or a priority ranking. The two methods studied here each use a different approach to achieve this objective. For the CI method, an arithmetic formula takes into account the importance of the dam, the relative importance of the monitoring activity or device and the field derived condition index for the given activity or device. Across a certain number of dams, the comparison of resulting computed values produces a ranking for the proposed corrective actions. In the case of Irstea, a decision tree permits definition of the 
Author-produced version of the article published in European Journal of Environmental and Civil Engineering, 2014, 18 (1), $87-105$. The original publication is available at http://www.tandfonline.com/toc/tece20/18/1

DOI: $10.1080 / 19648189.2013 .850188$

applicable schedule for the corrective action. This tree remains valid whatever the type of data considered: visual observations, instrumentation data, etc.

\section{Illustrations}

The actions defined by the experts show strong similarities (cf. Table 9). They correspond to inspection, maintenance and repair actions routinely performed around dams.

[Table 9 near here]

In the case of the CI method, corrective actions need to be prioritised. This ranking is determined by the following formula (Hydro-Québec, 2005):

$$
P R_{M D_{i, j}}=I_{D a m_{j}} \cdot I_{M D_{i, j}} \cdot\left(100-C I_{M D_{i, j}}\right)
$$

with:

- $I_{\text {Dam }_{j}}$ : importance of dam j. This term is calculated according to Hydro-Québec standard SB-06-02-00. The importance of a given structure is normalised in relation to the highest score in the group of dams;

- $I_{M D_{i, j}}$ : relative importance of a given monitoring activity or device $\left(\mathrm{MD}_{\mathrm{i}}\right)$ for dam $\mathrm{j} . \mathrm{It}$ is a measurement of the importance of the monitoring activity or device in identification of potential dam failure precursor signs. This term is assessed by taking into account:

(1) relative probabilities of the expected failure modes for the dam (overtopping, internal erosion, surface erosion, mass movement); 
(2) the importance of adverse conditions defined as undesirable events that occur at a specific location on the dam, and closely associated with failure modes (loss of freeboard due to overtopping; internal erosion through the embankment or the foundation, etc.);

(3) the importance of monitoring system indicators to signal the presence or absence of an adverse conditions. Deterioration of the upstream slope, crest deformation, uncontrolled percolation and interstitial pressure are examples of these rather generic indicators;

(4) the importance of monitoring activities or devices to assess the different monitoring system indicators. Among the MD, mention can be made of inspection of the upstream slope and crest, flow rate readings, piezometric levels measurements, etc.;

- the values of these four elements are assigned from a set of rules defined by a group of experts (Hydro-Québec, 2005);

- $C_{M D_{i, j}}:$ condition index of $\mathrm{MD}_{\mathrm{i}}$ for $\mathrm{dam}_{\mathrm{j}}$.

Equation (4) with $P R_{M D_{i, j}}>0$ allows classification and direct comparison of all the MD and establishing priorities for maintenance actions on them. Classification of priority rankings privileges the most significant MD on the most important dams that are in the worst condition.

A schedule is drawn up in the method developed by Irstea: the corrective actions are classified in categories ranging from "emergency action", "short term action", "medium term action" to "no action". A decision tree is built to formalise the practices of experts. This also 
Author-produced version of the article published in European Journal of Environmental and Civil Engineering, 2014, 18 (1), 87-105. The original publication is available at http://www.tandfonline.com/toc/tece20/18/1 DOI: $10.1080 / 19648189.2013 .850188$

entails ranking: the classification is performed as a function of the quality score and the values assigned to the criteria and weight of each of these criteria (essential or important) as defined for the ELECTRE TRI method (cf. Table 8).

\section{Discussion}

In both methods, the definition of corrective actions is based on proposals made by a group of experts. Thus it is once again necessary to call on a group that is available and ready to collaborate.

Other methodologies could be considered, especially:

- to prioritise actions, optimisation algorithms and multi-criteria decision-aids can be formulated;

- to define types of corrective actions, it is possible to use IF-THEN rules.

\section{Discussion}

Table 10 summarises the different methodological choices made in the two approaches seen in this analysis. This table could be used as the basis for a study focused on data quality for other civil engineering structures. Obviously, the methodologies proposed in the right hand column are not the only possible ones and others could be proposed depending on the case, as seen previously.

[Table 10 near here] 


\section{Conclusion}

This article presents an approach aimed at improving the quality of the data used during analyses of dam performance. It was illustrated by two methods developed independently.

This approach works in three phases: definition of the study framework to allow identifying pertinent data in relation with a stated objective, then the assessment of this data, and, finally, data quality control. Assessing quality is done as a function of the defined quality analysis criteria combined with the data selected, the definition of a criteria assessment scale, the aggregation of criteria to obtain a global quality score or a condition index. The aim of controlling data quality is to propose corrective actions linked to a schedule or a priority ranking.

The collection and formalisation of knowledge constitute the first step of the methodological approaches used in the Irstea and Hydro-Québec methods: they require the presence of a panel of available experts. This board subsequently plays an important role in the validation phase during which the algorithm output is compared to the data appraised by the experts.

The differences observed between the Irstea and Hydro-Québec methods originate from the initial objectives of the approaches: for Irstea, it is to assess the entire measurement system, whereas the method used by Hydro-Québec concerns only the ranking of maintenance/repair actions for the dam monitoring system. This leads to different methodological choices that are nonetheless adapted to the case on hand. Thus, the choice of aggregation method depends on the number of criteria studied, which in turn depends on the 
Author-produced version of the article published in European Journal of Environmental and Civil Engineering, 2014, 18 (1), 87-105. The original publication is available at http://www.tandfonline.com/toc/tece20/18/1

DOI: 10.1080/19648189.2013.850188

scope of the system studied (MS or MS and DPS), and the phase of the life-cycle considered

(design, construction, operation).

\section{References}

AFNOR (2011). NF ISO/CEI GUIDE 99 - International vocabulary of metrology - Basic and general concepts and associated terms (VIM).

Andersen, G. R. \& Torrey, V. H. (1995). Function-based Condition Index for embankment dams. Journal of Geotechnical Engineering, 121, 579-588.

Andersen, G. R., Chouinard, L. E., Hover, W. H. \& Cox, C. W. (2001). Risk indexing tool to assist in prioritizing improvements embankment dam inventories. Journal of Geotechnical and Geoenvironnemental Engineering, 127, 325-334.

Ben Armor, S. \& Martel, J. M. (2004). Le choix d'un langage de modélisation des imperfections de l'information en aide à la décision. Paper presented at the Congrès de l'ASAC, Québec, Canada.

Bouchon-Meunier, B. (1999). La logique floue. Presses Universitaires de France.

Brito, A. J., Almeida, A. T. \& Mota, C. M. M. (2010). A multicriteria model for risk sorting of natural gas pipelines based on ELECTRE TRI integrating Utility Theory. European Journal of Operational Research, 200, 812-821.

Cajete, J. \& Gil, A. (2000). Importance of visual inspections in dam safety. Experiences of Iberdola, S.A. Paper presented at the 20th International Congress on Large Dams, Beijing, China.

Chou, S. A., Chen, C. C., Wang, J., Chen, K. C. \& Chen, L. M. (2001). A knowledge-based system for dam safety assessment in Taiwan. Paper presented at the Symposium report on the 2nd Worldwide ECCE Symposium "Information and Communication Technology in the Practice of Building and Civil Engineering", Espoo, Finland.

Curt, C., Peyras, L. \& Boissier, D. (2010). A knowledge formalization and aggregationbased method for the assessment of dam performance. Computer-aided Civil and Infrastructure Engineering, 25, 171-183.

Curt, C., Talon, A. \& Mauris, G. (2011). A dam assessment support system based on physical measurements, sensory evaluations and expert judgements. Measurement, 44, 192201.

Curt, C. \& Talon, A. (2013). Assessment and Control of the Quality of Data Used during Dam Reviews by Using Expert Knowledge and the ELECTRE TRI Method. Journal of Computing in Civil Engineering, 27, 10-17.

Degoutte, G. (Ed.) (2002).Small dams - Guidelines for Design, Construction and Monitoring. Cemagref Editions.

Dibiagio, E. (2000). Monitoring of dams and their foundations. Paper presented at the 20th Congress on Large dams, Beinjing, China.

Foster, M., Fell, R. \& Spannagle, M. (2000a). The statistics of embankment dam failures and accidents. Canadian Geotechnical Journal, 37, 1000-1024.

Foster, M., Fell, R. \& Spannagle, M. (2000b). A method for assessing the relative likelihood of failure of embankment dams by piping. Canadian Geotechnical Journal, 37, 1025-1061.

Hydro-Québec (2005). Guide d'implantation des indices de condition - Barrages en remblai (document interne).

ICOLD (1988). Dam monitoring - General recommendations. 
Author-produced version of the article published in European Journal of Environmental and Civil Engineering, 2014, 18 (1), 87-105. The original publication is available at http://www.tandfonline.com/toc/tece20/18/1

DOI: 10.1080/19648189.2013.850188

Kreuzer, H. (2000). The use of risk analysis to support dam safety decisions and management. Paper presented at the 20th International Congress on Large Dams, Beijing, China.

Maystre, L. Y., Pictet, J. \& Simos, J. (1994). Méthodes multicritères ELECTRE. Presses Polytechniques Romandes.

Merad, M., Verdel, T. R., B. \& Kouniali, S. (2004). Use of multi-criteria decision-aids for risk zoning and management of large area subjected to mining-induced hazards. Tunnelling and Undergound Space Technology, 19, 125-138.

Miller, G. (1994). The Magical Number Seven, Plus or Minus Two: Some Limits on Our Capacity for Processing Information. Psychological Review, 101, 343-352.

Mousseau, Y. \& Slowinski, R. (1998). Inferring an ELECTRE TRI model from assignment examples. Journal of Global optimization, 12, 157-174.

Nafi, A. \& Werey, C. (2009). Aide à la décision multicritère pour la hiérarchisation de tronçons d'assainissement dans le cadre d'une gestion patrimoniale. Revue Canadienne de Génie Civil, 36, 1207-1220.

Peyras, L., Royet, P. \& Boissier, D. (2006). Dam ageing diagnosis and risk analysis: Development of methods to support expert judgement. Canadian Geotechnical Journal, 43, 169-186.

Peyras, L., Gervais, R., Serre, D., Chouinard, L., Diab, Y. \& Tourment, R. (2011). Condition evaluation of water retaining structures by a functional approach. Comparative practices in Canada and France. European Journal of Civil and Environmental Engineering, 15, 335-356.

Pimenta, L. \& Silva Gomes, A. (2000). Monte Da Rocha Dam - Analysis of monitoring results. Paper presented at the 20th International Congress on Large Dams, Beijing, China.

Roy, B. (1985). ELECTRE TRI. In Méthodologie Multicritère d'Aide à la Décision. Economica.

Royet, P. (2006). La surveillance et l'entretien des petits barrages. Cemagref.

Serre, D., Peyras, L., Curt, C., Boissier, D. \& Diab, Y. (2007). Evaluation des ouvrages hydrauliques de génie civil. Canadian Geotechnical Review, 44, 1298-1313.

Talon, A., Curt, C. \& Boissier, D. (in press). Performance assessment based on evidence theory and fuzzy logics: Application to building and dam performance. Journal of Computing in Civil Engineering, doi: 10.1061/(ASCE)CP.1943-5487.0000255.

Villemeur, A. (1991). Reliability, Availability, Maintainability Safety Assessment. John Wiley \& Sons Ltd. 
Author-produced version of the article published in European Journal of Environmental and Civil Engineering, 2014, 18 (1), 87-105. The original publication is available at http://www.tandfonline.com/toc/tece20/18/1

DOI: 10.1080/19648189.2013.850188

30 EJECE. Volume $\mathrm{X}$ - no. x/year

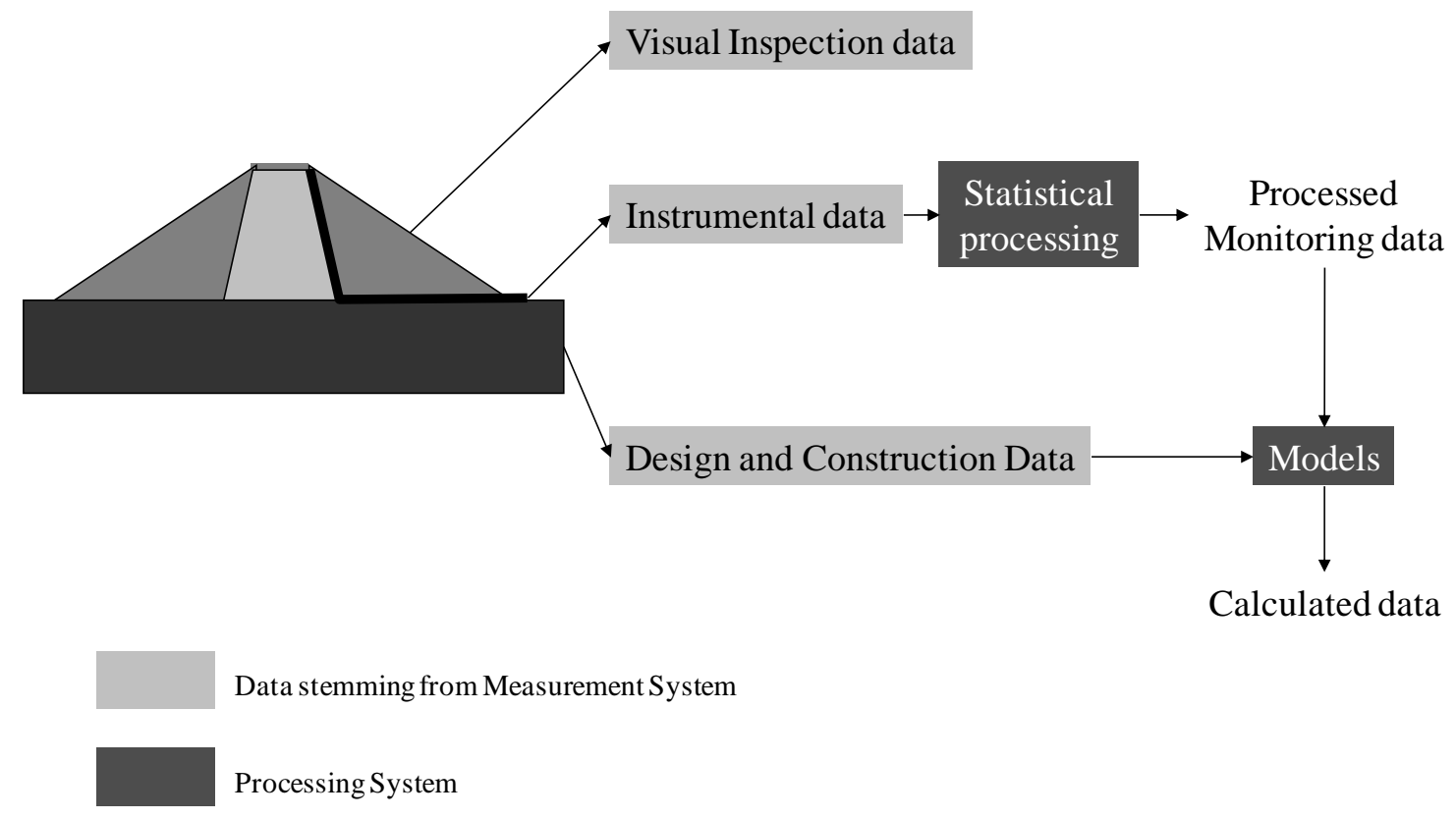

Figure 1. Data used during the assessment of the performance of a dam 
Author-produced version of the article published in European Journal of Environmental and Civil Engineering, 2014, 18 (1), 87-105. The original publication is available at http://www.tandfonline.com/toc/tece20/18/1

DOI: 10.1080/19648189.2013.850188

Approach to improving data quality 31

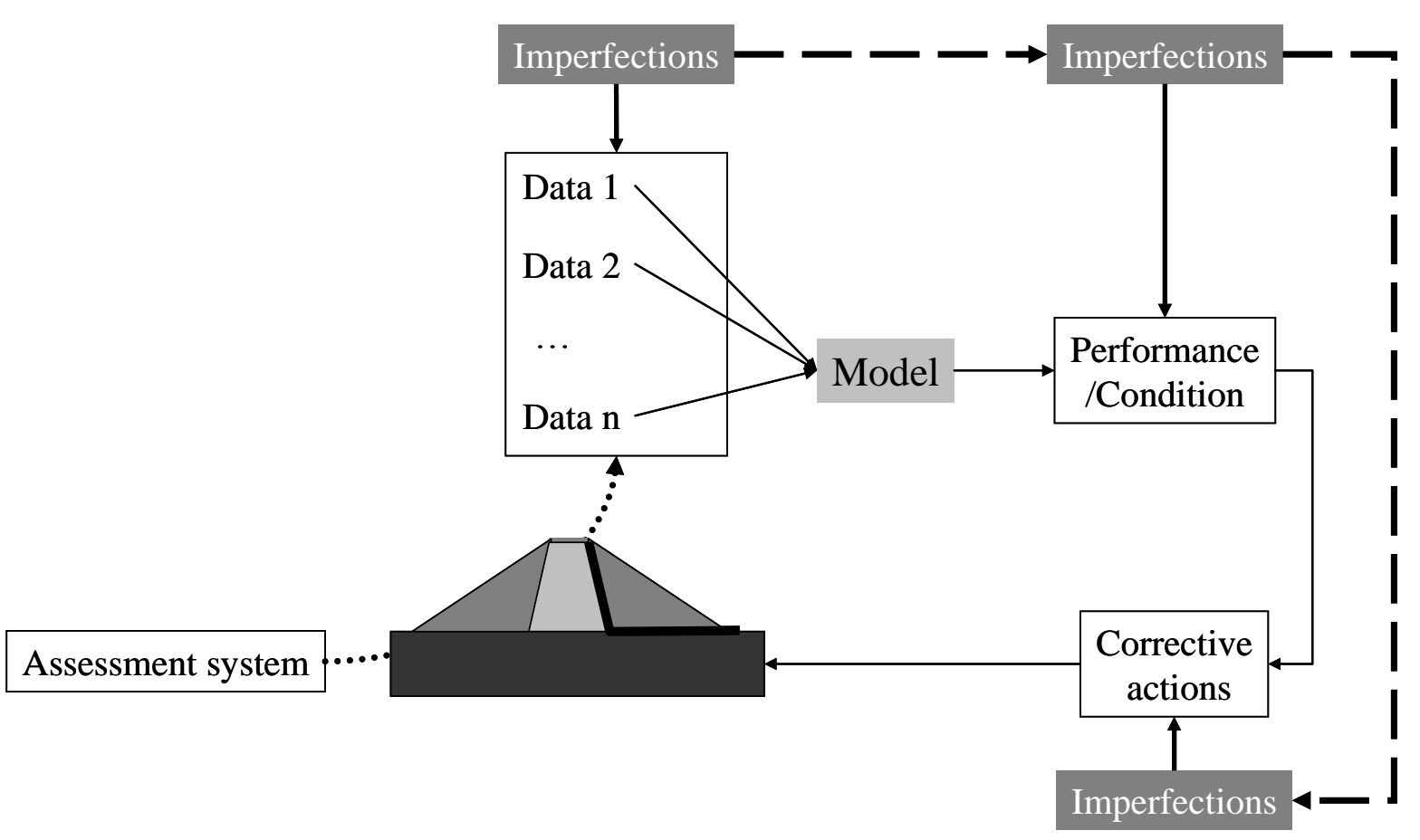

Figure 2. Determination of the performance/condition of a dam and the propagation of imperfections 
Author-produced version of the article published in European Journal of Environmental and Civil Engineering, 2014, 18 (1), 87-105. The original publication is available at http://www.tandfonline.com/toc/tece20/18/1

DOI: $10.1080 / 19648189.2013 .850188$

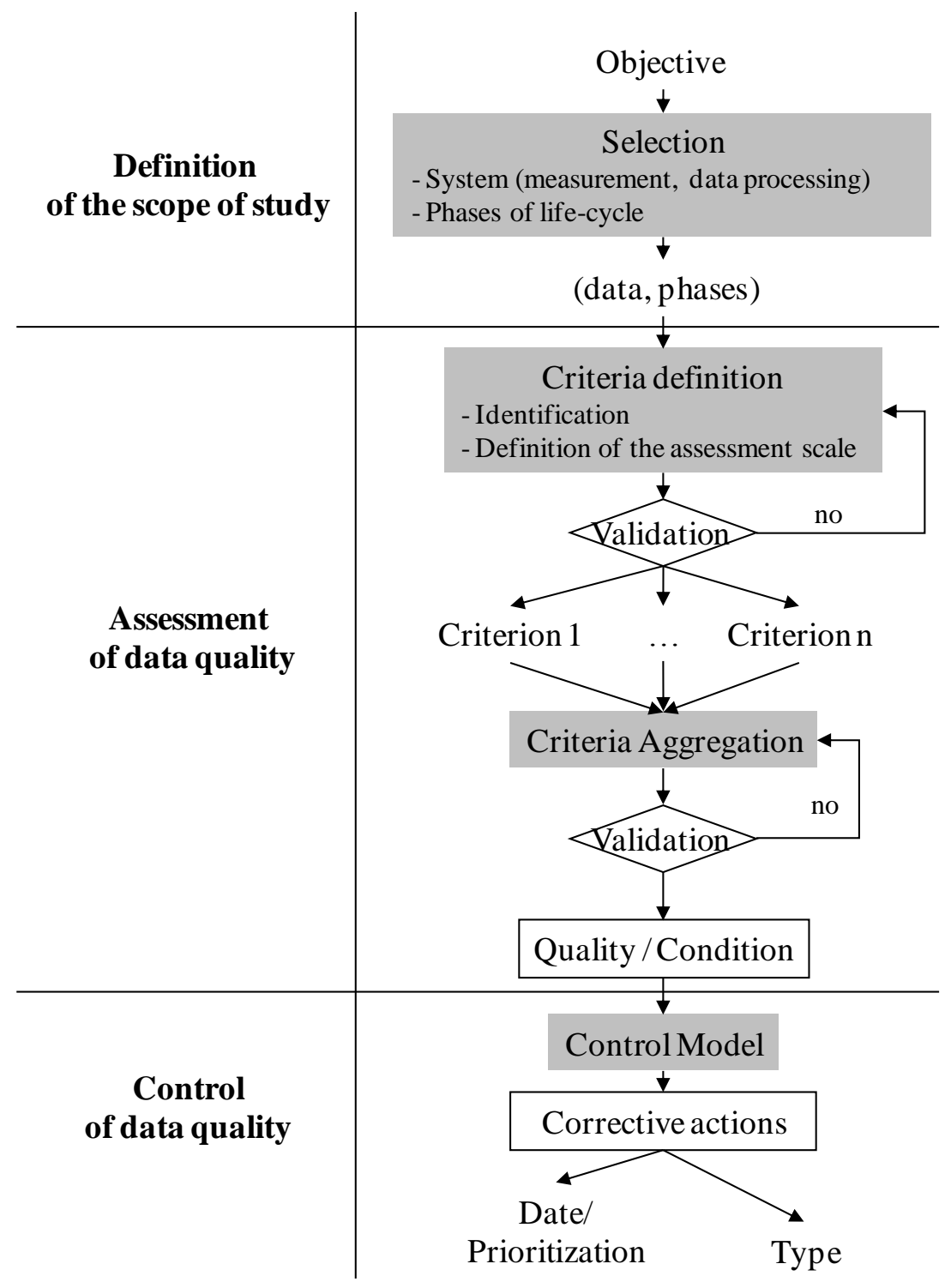

Figure 3. Principle of the approach to assessing and controlling data quality 
Author-produced version of the article published in European Journal of Environmental and Civil Engineering, 2014, 18 (1), 87-105. The original publication is available at http://www.tandfonline.com/toc/tece20/18/1

DOI: 10.1080/19648189.2013.850188

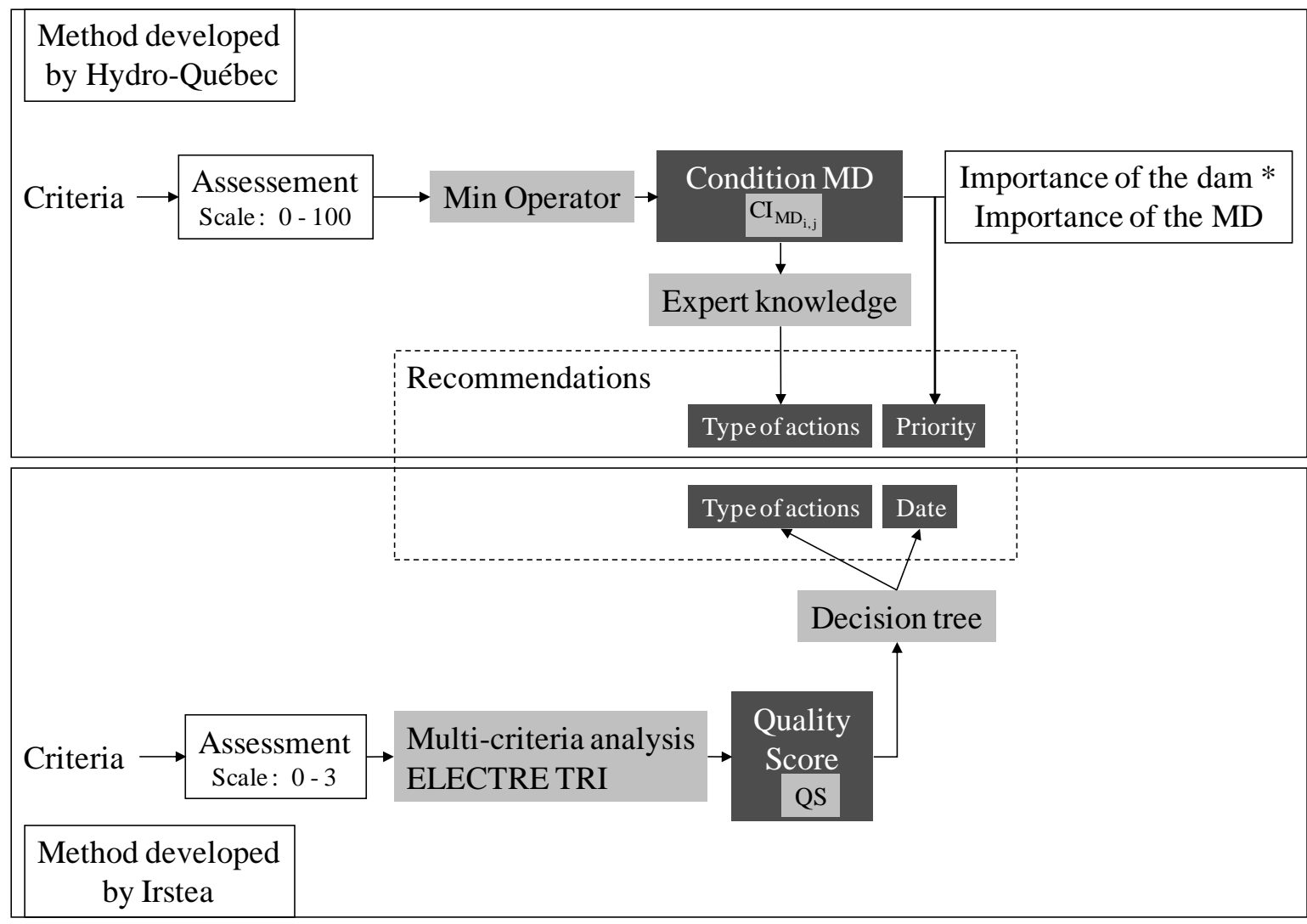

Figure 4. Detail of the methods developed by Hydro-Québec and by Irstea 
Author-produced version of the article published in European Journal of Environmental and Civil Engineering, 2014, 18 (1), $87-105$. The original publication is available at http://www.tandfonline.com/toc/tece20/18/1

DOI: 10.1080/19648189.2013.850188

EJECE. Volume $\mathrm{X}-$ no. $\mathrm{x} / \mathrm{year}$

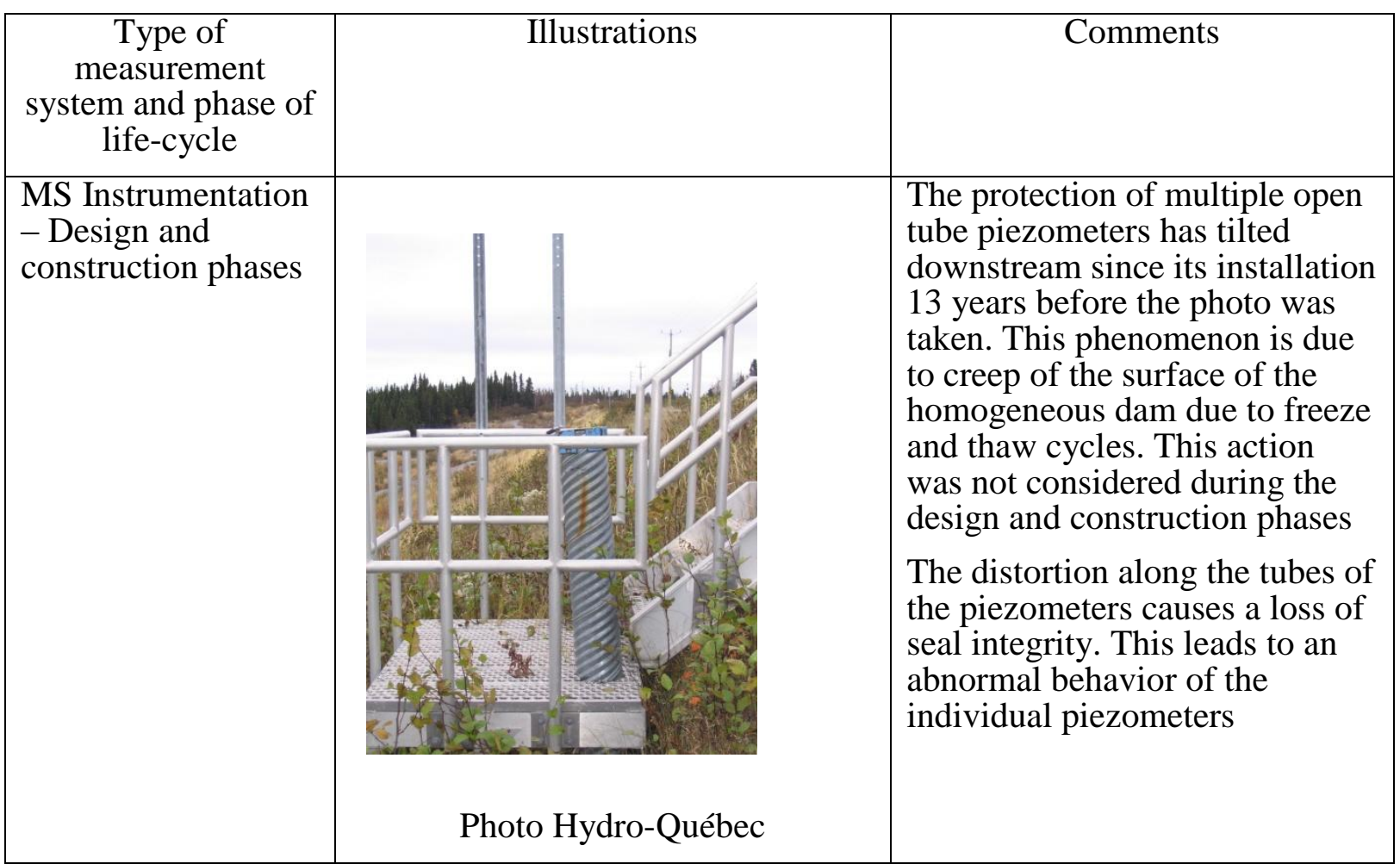

Table 1. Example of measurement system failures - Design and construction phases 
Author-produced version of the article published in European Journal of Environmental and Civil Engineering, 2014, 18 (1), $87-105$. The original publication is available at http://www.tandfonline.com/toc/tece20/18/1

DOI: 10.1080/19648189.2013.850188

Approach to improving data quality

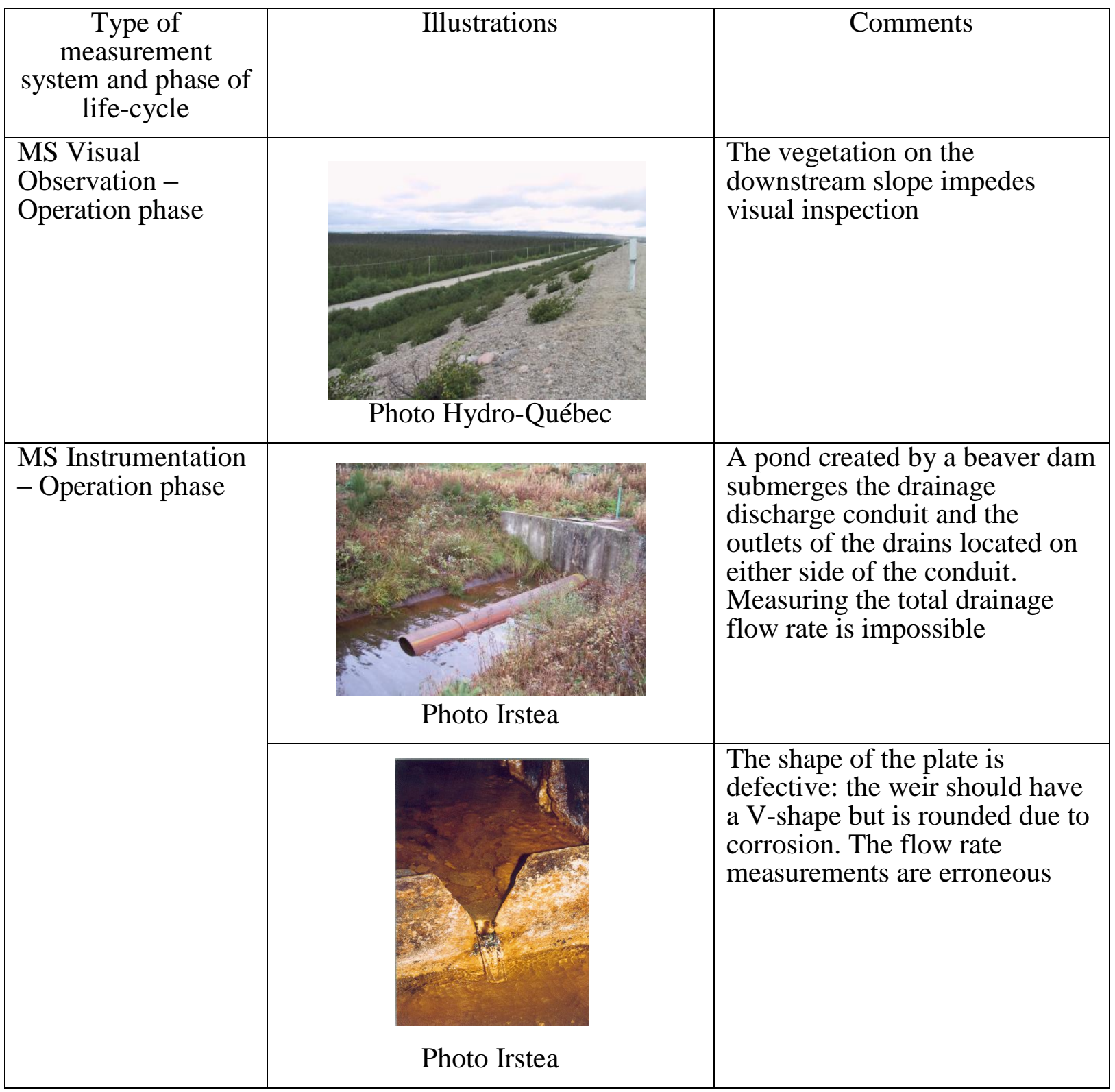

Table 2. Examples of measurement system failures - Operation phase 
Author-produced version of the article published in European Journal of Environmental and Civil Engineering, 2014, 18 (1), $87-105$. The original publication is available at http://www.tandfonline.com/toc/tece20/18/1

DOI: 10.1080/19648189.2013.850188

\begin{tabular}{|c|c|c|}
\hline $\begin{array}{c}\text { Categories of } \\
\text { criteria }\end{array}$ & Criteria used by Irstea & Criteria used by Hydro- Québec \\
\hline $\begin{array}{l}\text { MS - Design } \\
\text { and } \\
\text { Construction } \\
\text { Phases }\end{array}$ & 2 criteria & \\
\hline $\begin{array}{l}\text { MS - Operation } \\
\text { Phase - criteria }\end{array}$ & $\begin{array}{l}\text { Resolution - Measurement } \\
\text { precision }\end{array}$ & Inexact data \\
\hline $\begin{array}{l}\text { linked to the } \\
\text { device }\end{array}$ & $\begin{array}{l}\text { Representativeness } \\
\text { Condition }\end{array}$ & $\begin{array}{l}\text { Absence of data } \\
\text { Device not functioning }\end{array}$ \\
\hline & Frequency of measurements & Incorrect frequencies \\
\hline $\begin{array}{l}\text { MS - Operation } \\
\text { Phase - criteria } \\
\text { linked to the } \\
\text { inspector }\end{array}$ & 3 criteria & \\
\hline DPS & 3 criteria & \\
\hline
\end{tabular}

Table 3. Comparison of the criteria used by Irstea and Hydro-Québec for data resulting from instrumentation 
Author-produced version of the article published in European Journal of Environmental and Civil Engineering, 2014, 18 (1), 87-105. The original publication is available at http://www.tandfonline.com/toc/tece20/18/1

DOI: $10.1080 / 19648189.2013 .850188$

Approach to improving data quality

\begin{tabular}{|c|c|c|}
\hline $\begin{array}{l}\text { Categories of } \\
\text { criteria }\end{array}$ & Criteria used by Irstea & Criteria used by Hydro- Québec \\
\hline \multirow{3}{*}{$\begin{array}{l}\text { MS - Criteria } \\
\text { linked to the } \\
\text { accessibility of } \\
\text { the data }\end{array}$} & $\begin{array}{l}\text { Conditions of visibility - } \\
\text { accessibility }(\mathrm{C} 1)\end{array}$ & $\begin{array}{l}\text { Inspection surface: } \\
\text { Accessibility and surface inspected }\end{array}$ \\
\hline & Climatic conditions (C2) & $\begin{array}{l}\text { Climatic conditions: } \\
\text { Documented in inspection report } \\
\text { but not used directly in CI method }\end{array}$ \\
\hline & & Frequency of inspection \\
\hline $\begin{array}{l}\text { MS } \\
\text { Criteria linked } \\
\text { to the inspector }\end{array}$ & $\begin{array}{l}\text { Analysis/Reactivity of observer (C3) } \\
\text { Reliability of material resources } \\
\text { implemented for the observation } \\
\text { (C4) } \\
\text { Route - time devoted to visit (C5) } \\
\text { Quality of report (C6) } \\
\text { Change of observer (C7) } \\
\text { Conditions taken into account } \\
\text { (season, level of reservoir) (C8) }\end{array}$ & \\
\hline
\end{tabular}

Table 4. Comparison of criteria used by Irstea and Hydro-Québec for the data resulting from visual observation 
Author-produced version of the article published in European Journal of Environmental and Civil Engineering, 2014, 18 (1), 87-105. The original publication is available at http://www.tandfonline.com/toc/tece20/18/1

DOI: 10.1080/19648189.2013.850188

Presence of a leak on the downstream slope of the embankment is difficult to detect due to invasive vegetation.

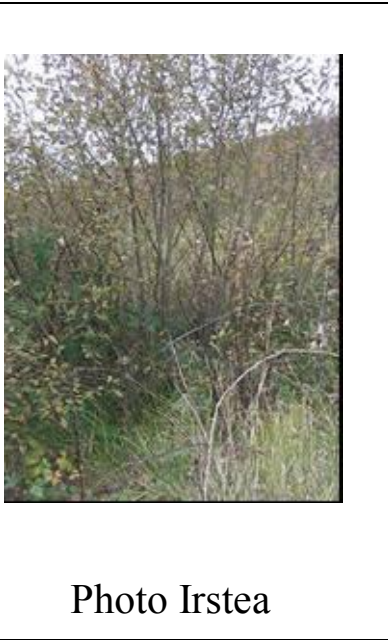

Score

of criterion "Accessibility - Visibility conditions" $=2$ (poor)

Table 5. Irstea method - Scoring of criterion: "Conditions of visibility - Accessibility" for the visual data "Presence of leak on the downstream slope of the embankment" 


\begin{tabular}{|c|c|c|c|}
\hline $\begin{array}{l}\text { REMR } \\
\text { recommended action }\end{array}$ & $\begin{array}{l}\text { Condition } \\
\text { index }(C I)\end{array}$ & \multicolumn{2}{|c|}{ REMR Description of the condition } \\
\hline \multirow{2}{*}{$\begin{array}{l}\text { No immediate action } \\
\text { required }\end{array}$} & 85 to 100 & $\begin{array}{l}\text { No noticeable defects. Some ageing } \\
\text { or wear may be visible. }\end{array}$ & Excellent \\
\hline & 70 to 84 & $\begin{array}{l}\text { Only minor deterioration or defects } \\
\text { are evident. }\end{array}$ & Good \\
\hline \multirow{2}{*}{$\begin{array}{l}\text { An economic analysis } \\
\text { of repair alternatives } \\
\text { is recommended to } \\
\text { determine the } \\
\text { appropriate action. }\end{array}$} & 55 to 69 & $\begin{array}{l}\text { Some deterioration or defects are } \\
\text { evident, but function is not } \\
\text { significantly affected. }\end{array}$ & Fair \\
\hline & 40 to 54 & $\begin{array}{l}\text { Moderate deterioration but function } \\
\text { is still adequate. }\end{array}$ & Marginal \\
\hline \multirow{3}{*}{$\begin{array}{l}\text { A detailed evaluation } \\
\text { is required to } \\
\text { determine the need for } \\
\text { repair, rehabilitation } \\
\text { or reconstruction. }\end{array}$} & 25 to 39 & $\begin{array}{l}\text { Serious deterioration in at least some } \\
\text { portions of the structure. Function is } \\
\text { inadequate. }\end{array}$ & Poor \\
\hline & 10 to 24 & $\begin{array}{lll}\text { Extensive } & \text { deterioration, } \\
\text { functional. } & & \end{array}$ & Very poor \\
\hline & 0 to 9 & $\begin{array}{l}\text { No longer functions, general failure } \\
\text { or complete failure of a major } \\
\text { component. }\end{array}$ & Failed \\
\hline
\end{tabular}

Table 6. Condition Index method - REMR scale and description of the condition with associated recommended actions applied to the Measurement System 
Author-produced version of the article published in European Journal of Environmental and Civil Engineering, 2014, 18 (1), $87-105$. The original publication is available at http://www.tandfonline.com/toc/tece20/18/1

DOI: 10.1080/19648189.2013.850188

40 EJECE. Volume X - no. x/year

Arrival of water difficult to trace in the vegetation in the downstream area.

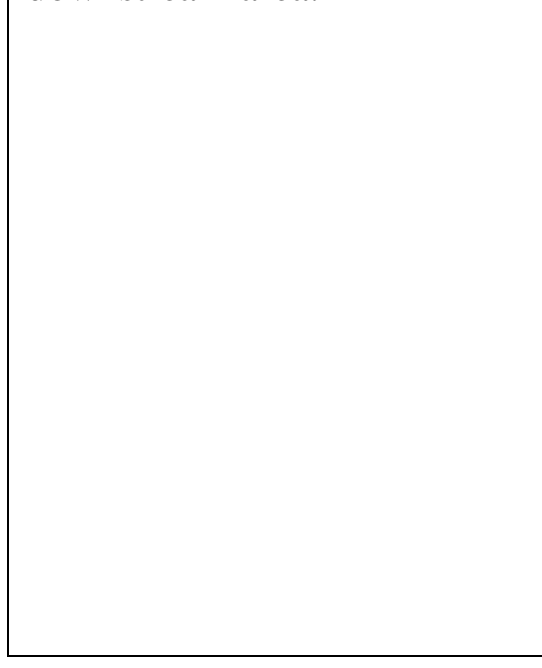

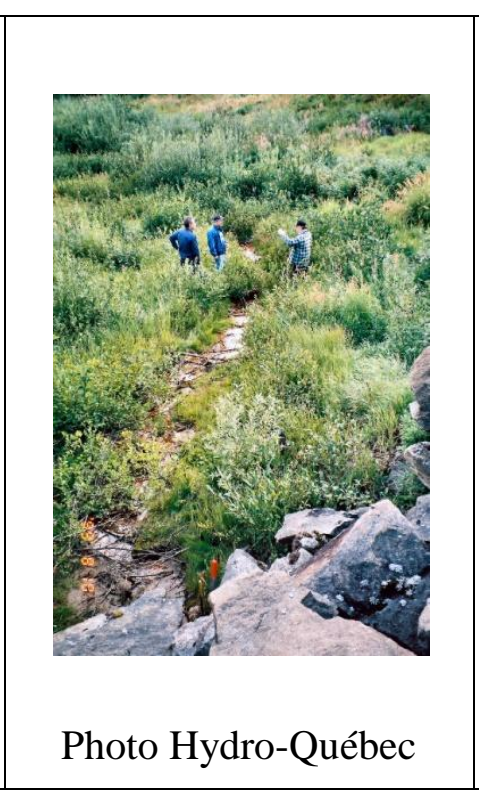

Score of criterion Inspection of the downstream area $=50$ (equivalent to the label REMR = marginal)

Table 7. Hydro-Québec method - Scoring of the criterion "Surface inspected in the downstream area" 
Author-produced version of the article published in European Journal of Environmental and Civil Engineering, 2014, 18 (1), $87-105$. The original publication is available at http://www.tandfonline.com/toc/tece20/18/1

DOI: 10.1080/19648189.2013.850188

\begin{tabular}{|l|l|l|l|l|l|l|l|l|l|}
\hline & C1 & C2 & C3 & C4 & C5 & C6 & C7 & C8 & QS \\
\hline Weight & 18.2 & 0 & 18.2 & 9.1 & 9.1 & 18.2 & 9.1 & 18.2 & \\
\hline Score & 1 & 0 & 0 & 0 & 1 & 1 & 3 & 2 & 3 \\
\hline
\end{tabular}

Table 8. Irstea method - Example of criteria aggregation results for visual data "Cracks in the joints between blocks" - $\mathrm{C}_{\mathrm{i}}$ : assessment criteria of visual data - QS: Quality Score 
Author-produced version of the article published in European Journal of Environmental and Civil Engineering, 2014, 18 (1), $87-105$. The original publication is available at http://www.tandfonline.com/toc/tece20/18/1

DOI: 10.1080/19648189.2013.850188

42 EJECE. Volume $\mathrm{X}$ - no. x/year

\begin{tabular}{|l|l|l|}
\hline & Hydro-Québec Method & Irstea Method \\
\hline $\begin{array}{l}\text { Data resulting from visual } \\
\text { observation }\end{array}$ & Carry out vegetation limitation & Clear the downstream slope \\
\hline $\begin{array}{l}\text { Data obtained from } \\
\text { instrumentation }\end{array}$ & $\begin{array}{l}\text { Clean the open standpipe } \\
\text { piezometers at the downstream } \\
\text { toe of the dam } \\
\text { Repair the faulty piezometers }\end{array}$ & $\begin{array}{l}\text { Clean the drain outlets. } \\
\text { Repair/replace the faulty } \\
\text { instrument }\end{array}$ \\
\hline
\end{tabular}

Table 9. Examples of actions proposed by the two methods 
Author-produced version of the article published in European Journal of Environmental and Civil Engineering, 2014, 18 (1), $87-105$. The original publication is available at http://www.tandfonline.com/toc/tece20/18/1

DOI: 10.1080/19648189.2013.850188

Approach to improving data quality

\begin{tabular}{|l|l|l|}
\hline \multicolumn{1}{|c|}{ Phases } & \multicolumn{1}{|c|}{ Steps } & \multicolumn{1}{c|}{ Methodologies } \\
\hline $\begin{array}{l}\text { Assessment of } \\
\text { data quality }\end{array}$ & Determination of criteria & $\begin{array}{l}\text { Safety type approach to operation } \\
\text { linked to collection and validation by } \\
\text { a group of experts } \\
\text { Definition by a panel of experts }\end{array}$ \\
\cline { 2 - 3 } & Definition of the scoring scale & Definition by a panel of experts \\
\cline { 2 - 3 } & Aggregation of criteria & $\begin{array}{l}\text { Multi-criteria approaches } \\
\text { Mathematical operators (sum, } \\
\text { product, etc.) }\end{array}$ \\
\hline $\begin{array}{l}\text { Control of data } \\
\text { quality }\end{array}$ & Types of action & $\begin{array}{l}\text { Definition by a panel of experts } \\
\text { List predefined by a panel of experts }\end{array}$ \\
\cline { 2 - 3 } & $\begin{array}{l}\text { Definition of scheduling } \\
\text { priorities. }\end{array}$ & $\begin{array}{l}\text { Priority calculated by mathematical } \\
\text { operator from data supplied by } \\
\text { predefined tables adapted to the case } \\
\text { dealt with by the experts } \\
\text { Decision tree defined by a panel of } \\
\text { experts }\end{array}$ \\
\hline & & \\
\hline
\end{tabular}

Table 10. Methods used to assess and control the quality of data for dam analyses 